OPEN ACCESS

Edited by:

Raquel Nieto,

University of Vigo, Spain

Reviewed by:

Gabriela Mora Rojas, University of Costa Rica, Costa Rica

Pedro Ribera,

Universidad Pablo de Olavide, Spain

*Correspondence:

Victor Magaña

victormr@unam.mx

Specialty section:

This article was submitted to

Atmospheric Science,

a section of the journal

Frontiers in Earth Science

Received: 20 September 2017

Accepted: 20 February 2018

Published: 06 March 2018

Citation:

Dominguez C and Magaña V (2018) The Role of Tropical Cyclones in

Precipitation Over the Tropical and

Subtropical North America.

Front. Earth Sci. 6:19.

doi: 10.3389/feart.2018.00019

\section{The Role of Tropical Cyclones in Precipitation Over the Tropical and Subtropical North America}

\author{
Christian Dominguez ${ }^{1}$ and Victor Magaña ${ }^{2 *}$ \\ ${ }^{1}$ Posgrado en Ciencias de la Tierra, Universidad Nacional Autónoma de Mexico, Mexico, Mexico, ${ }^{2}$ Instituto de Geografía, \\ Universidad Nacional Autónoma de Mexico, Mexico, Mexico
}

Tropical cyclones (TCs) are essential elements of the hydrological cycle in tropical and subtropical regions. In the present study, the contribution of TCs to seasonal precipitation around the tropical and subtropical North America is examined. When TC activity over the tropical eastern Pacific (TEP) or the Intra Americas Seas (IAS) is below (abovenormal), regional precipitation may be below (above-normal). However, it is not only the number of TCs what may change seasonal precipitation, but the trajectory of the systems. TCs induce intense precipitation over continental regions if they are close enough to shorelines, for instance, if the TC center is located, on average, less than 500 $\mathrm{km}$-distant from the coast. However, if TCs are more remote than this threshold distance, the chances of rain over continental regions decrease, particularly in arid and semi-arid regions. In addition, a distant TC may induce subsidence or produce moisture divergence that inhibits, at least for a few days, convective activity farther away than the threshold distance. An analysis of interannual variability in the TCs that produce precipitation over the tropical and subtropical North America shows that some regions in northern Mexico, which mostly depend on this effect to undergo wet years, may experience seasonal negative anomalies in precipitation if TCs trajectories are remote. Therefore, TCs (activity and trajectories) are important modulators of climate variability on various time scales, either by producing intense rainfall or by inhibiting convection at distant regions from their trajectory. The impact of such variations on water availability in northern Mexico may be relevant, since water availability in dams recovers under the effects of TC rainfall. Seasonal precipitation forecasts or climate change scenarios for these regions should take into account the effect of TCs, if regional adaptation strategies are implemented.

Keywords: tropical cyclones, tropical cyclone trajectory, moisture flux, precipitation anomaly, water reservoirs

\section{INTRODUCTION}

Tropical cyclones (TCs) are frequently associated with disasters given the adverse impacts that the related intense winds, storm surges, and heavy rainfall have on vulnerable regions (Smith et al., 2009). In some places though, TCs have a positive effect in terms of becoming the primary source of water to refill dams and other surface water reservoirs (Aguilar-Benitez, 2011). Therefore, they are key atmospheric phenomena in the hydrological cycle of several tropical and semi-arid regions around the world (Trenberth and Fasullo, 2007). Several studies show that the contribution of TCs to seasonal or annual rainfall may be up to $50 \%$ over some continental regions, depending 
on the evolution of their wind field, topographical effects, atmospheric humidity and size, but mainly, the closeness of these systems to shorelines (Cerveny and Newman, 2000; Rogers et al., 2000; Jiang and Zipser, 2010). Although most analyses focus on only estimating their impact in seasonal precipitation, they may also induce the opposite effect (inhibit convection).

Some studies have examined how TCs may result in a decrease of seasonal precipitation (e.g., Shanko and Chamberlain, 1998) having a dual effect: inducing large amounts of precipitation in few days, or reducing seasonal precipitation due to their absence or distant trajectories. In this way, negative regional seasonal precipitation anomalies and even meteorological droughts can occur in years of diminished TC activity or when the dominant TC trajectories are distant from continental regions by inducing enhanced moisture divergence (Shanko and Chamberlain, 1998). However, these changes in regional circulations and precipitation are not always documented as important factors of seasonal precipitation for water planning.

The synoptic characteristics that modulate convective activity in TCs are associated with moisture flow convergence at low levels of the atmosphere and a radial outflow near the tropopause that leads to subsidence at a larger radius that the storm center (Willoughby, 1979). Two kinds of subsidence induced by TCs occur: (a) at the storm center, which is forced by the mechanic eye spin and enhanced convection due to the release of latent heat; and (b) weaker subsidence outside the core of the system that is forced mechanically (Emanuel, 1997; Zhang and Kieu, 2005). The latter may produce clear skies in neighboring regions to the TC system.

Shephard et al. (2007) found that TCs accounted from 8 to $17 \%$ of cumulative rainfall at different locations along the coastal zone of the southeastern United States. TCs that are close to Mexico may contribute from 20 to $60 \%$ of the observed seasonal rainfall for some coastal regions (Englehart and Douglas, 2001; Breña-Naranjo et al., 2015). This makes TCs an essential climatic element of the summer rainy season in Mexico (Jáuregui, 2003; Larson et al., 2005). However, TCs have a dual effect in terms of accumulated precipitation that needs to be assessed more comprehensively. For instance, easterly waves from the Atlantic are significant contributors to summer precipitation over the Intra Americas Seas (IAS) and the Mesoamerican regions (Magaña et al., 2003). At times, these systems become TCs and recurve in the middle of the Atlantic Ocean, transporting moisture into the subtropical mid-Atlantic Ocean, and reducing the chances of rain over the tropical and subtropical North America. Consequently, a larger TC activity in the Atlantic and even in the IAS does not necessarily mean more precipitation over the continental regions. The number of TCs forming in the North Atlantic or in the eastern Pacific may vary from 1 year to another in relation to low frequency climate variability.

TC activity in the Atlantic and the eastern Pacific Oceans from May to November is modulated by El Niño/Southern Oscillation (ENSO) (Magaña, 2004). During La Niña (El Niño), large (diminished) TC activity over the IAS may result in enhanced (decreased) precipitation over southern, central and northeastern Mexico (Magaña et al., 2003). TC activity also shows important interdecadal variations in relation to the Atlantic Multidecadal
Oscillation (AMO) and the Pacific Decadal Oscillation (PDO). The AMO and the PDO phases may also result in prolonged meteorological droughts over the North America (Méndez and Magaña, 2010). During these dry periods, one single TC event may provide enough rainfall in a region as to make its summer rainy season quasi-normal or above-normal in the middle of a prolonged meteorological drought. This was the case of the Hurricane Alex, 2010 or tropical storm Ingrid, 2013 that affected the northeast of Mexico and produced enough precipitation to turn into normal the precipitation statistics during that summer season and recover the levels of dams during a severe drought period (Sisto et al., 2015).

In arid and semiarid regions of northern Mexico, TCs are sources of water to recharge aquifers, rivers, lakes (Díaz et al., 2008), and dams (Aguilar-Benitez, 2011). For instance, Hurricane Alex made landfall on July 1st, 2010 and produced the amount of $446 \mathrm{~mm}$ in $24 \mathrm{~h}$ over the Monterrey Metropolitan Area, which is close to the average summer precipitation of the northeastern Mexico. TC Alex helped to recover El Cuchillo dam water levels to normal conditions, enough to provide this resource for several socioeconomic activities during the prolonged 20102012 drought (Magaña and Neri, 2012). Thus, TCs may be water suppliers during dry periods, ameliorating the effects of water crisis (Sisto et al., 2015). Including the effect of TCs in climate outlooks would be of great benefit in the water management plans where water distribution is frequently decided on a yearly basis, especially during periods of drought (Neri and Magaña, 2016).

For seasonal precipitation outlooks, TCs trajectories are as important as TC activity itself. The need for information on this subject is necessary, particularly in arid and semiarid regions of northwestern Mexico, where the average annual precipitation is around $400 \mathrm{~mm}$. Current seasonal climate prediction schemes rarely take into account the TC effect on accumulated rainfall for water availability projections, mainly because TC trajectories are hard to predict (Camargo et al., 2010). TC trajectories are primarily determined by the beta effect (Adem, 1956) and the dominant large-scale circulations (Hill and Lackmann, 2009), which could be adequately simulated by current climate models (e.g., Trenberth et al., 1998; Wang et al., 2015). Some schemes only predict the number of TCs and the potential intensity distribution during a season. However, for seasonal precipitation forecasts, TC intensity is less important than the number of systems and trajectories. Some of the rainiest TCs have been tropical storms or tropical depressions but have resulted in extreme rains of more than $300 \mathrm{~mm} /$ day, such as Stan in 2005 over the IAS (Pasch and Roberts, 2006). Therefore, estimating the contribution of TCs to accumulated seasonal or annual rainfall should consider the position (trajectory) and days that affect a region (Kubota and Chan, 2009). Kossin et al. (2010) related some TC tracks over the north Atlantic to the ENSO phase.

The main objective of this study is to investigate the positive and negative impacts of TCs on summer rainfall over the tropical and subtropical North America, considering not only their frequency, but their preferred tracks as elements that lead to wet or dry summer seasons. A diagnostic of such aspect of TCs should be included when seasonal predictions (outlooks) and regional climate change scenarios are developed. A more 
detailed analysis of this dual TC effect may help to understand low predictability for summer seasons of some regions of the world, such as northern Mexico (Gutzler et al., 2009).

This paper is organized as follows: in section Data and Methodology, the data used in the analyses are described (reanalysis, rain gauge station data, reservoir records, as well as TC data). The methodology followed to examine TC activity, including their preferred trajectories and impacts on precipitation is discussed. In section Results, an analysis of the contribution of various types of TC trajectory clusters to accumulated seasonal precipitation is presented. Preferred TC trajectories are also analyzed in terms of quasi-stationary circulations at the TC steering level. The impacts of TCs in water balances and their potential inclusion on seasonal precipitation forecast are also examined. Discussion and conclusions are given in section Discussion and Conclusions.

\section{DATA AND METHODOLOGY}

Historical records of TC activity for the second half of the twentieth century are available in the HURDAT database of the National Hurricane Center. HURDAT includes data on TCs tracks and their intensity. These data may be considered more accurate after the 1970s, when satellite observations are available (Vecchi and Knutson, 2007). Therefore, special emphasis for the analysis is given to data after 1979. Although the information on the intensity of the systems is given in terms of the SaffirSimpson scale, it is not considered relevant for the analyses, as there is not a direct relationship between TC intensity and its associated precipitation. TCs whose intensity is higher than tropical depression and whose location (center of the system) is in the domain of interest $\left(10^{\circ}-35^{\circ} \mathrm{N}\right.$ and $\left.120^{\circ}-70^{\circ} \mathrm{W}\right)$ were included in the analysis. Threshold-distances or radius of influence to define TC-related rainfall range from 400 to $1,000 \mathrm{~km}$ from the TC center (Englehart and Douglas, 2001; Jiang and Zipser, 2010; Breña-Naranjo et al., 2015). In general, a radius of influence of $500 \mathrm{~km}$ is considered adequate for most analyses of the influence of TCs on regional precipitation. The threshold distance may vary from one system to another, but this approximation has been considered adequate to estimate the TC contribution to rainfall (Jiang and Zipser, 2010).

Daily precipitation data comes from rain gauge stations in the domain of interest. The surface weather station data for Mexico was obtained from the Mexican Weather Service archives. The rest of the station data comes from more than 2,000 rain gauge stations, with at least 30 years of data for the 19792013 period, from the Global Historical Climatology Project (GHCP). Particular emphasis is given to the impact of TCs over precipitation in Mexico, where the density of precipitation information is at least one order of magnitude larger than in the surrounding regions.

Meteorological data to examine wind fields and moisture divergence were obtained from the European Centre for Medium-Range Weather Forecasts ERA-Interim (ERA-I) which have a T255 spectral resolution $(\sim 80 \mathrm{~km})$ on 60 vertical levels (Dee et al., 2011). The moisture flux information at lower atmospheric levels is relevant to relate precipitation over the continental and oceanic regions. For consistency, the ERA-I rainfall data are also used to complement rain-gauge data mainly over oceanic regions. This data is available from 1979 to present. In most cases, extreme rainfall related to TC activity corresponds to events of more than $50 \mathrm{~mm}$ day $^{-1}$. When compared with surface station data, the ERA interim data adequately captures the effect of TCs in precipitation, which makes them a good estimate of rainfall over oceanic regions as well.

TCs trajectories are grouped by their spatial-temporal characteristics using a probabilistic clustering technique, called Curve Clustering Toolbox (CCT) (Gaffney, 2004). The CCT of TC tracks takes into account length, location and geographical shape of the trajectories. Camargo et al. (2008) and Kossin et al. (2010) used this type of clustering approach to define dominant TC trajectories over the North Atlantic and tropical north Eastern Pacific Ocean (TEP). Four clusters for TC trajectories over the Atantic and four for the eastern Pacific were defined in the present analysis, in order to identify how these TC clusters affect the continental coasts. Following Englehart and Douglas (2001), a threshold distance from the TC center to the coastal region $(\sim 500 \mathrm{~km})$ was used to define a radius of influence where these tropical systems produce extreme rainfall. Composite analyses for the effect of each cluster during the JuneJuly-August-September-October (JJASO) period, considered in general terms as the summer rainy season, were constructed.

Specific regions over Mexico were considered to determine the impact of TCs on summer precipitation and water reservoirs. Four regions were selected according to their location and summer precipitation regimen: northeast, northwest, southeast and southwest of Mexico (Figure 1). Data of national reservoirs were obtained from the Mexican Water Administration archives (http://www.conagua.gob.mx/CONAGUA07/Contenido/

Documentos/Portada\%20BANDAS.htm). The reservoirs that had the longest record of daily data in the 1979-2013 period were taken into account for this study (Figure 1).

\section{RESULTS}

\section{TC Activity Over North America and Precipitation}

The contribution of TCs to seasonal precipitation in tropical and subtropical regions is well known (e.g., Jiang and Zipser, 2010). However in arid and semi-arid regions, as in northern Mexico, the effect of a land-falling or sufficiently close TC to shorelines, results in a significant contribution to the annual accumulated rainfall. Changes in TC activity impact may lead to large interannual variations in precipitation and water availability in some of these regions. The contribution of TCs in seasonal precipitation over Mexico was explored by using the rain-gauge station daily data and adding the rainfall when TCs are present at a distance less than the critical threshold of $500 \mathrm{~km}$ from the location of the station. For instance, the annual precipitation (from January to December) in the southern part of the Baja California peninsula is around $200 \mathrm{~mm}$ when there is no TC contribution to regional rainfall. However, when TCs affect the 


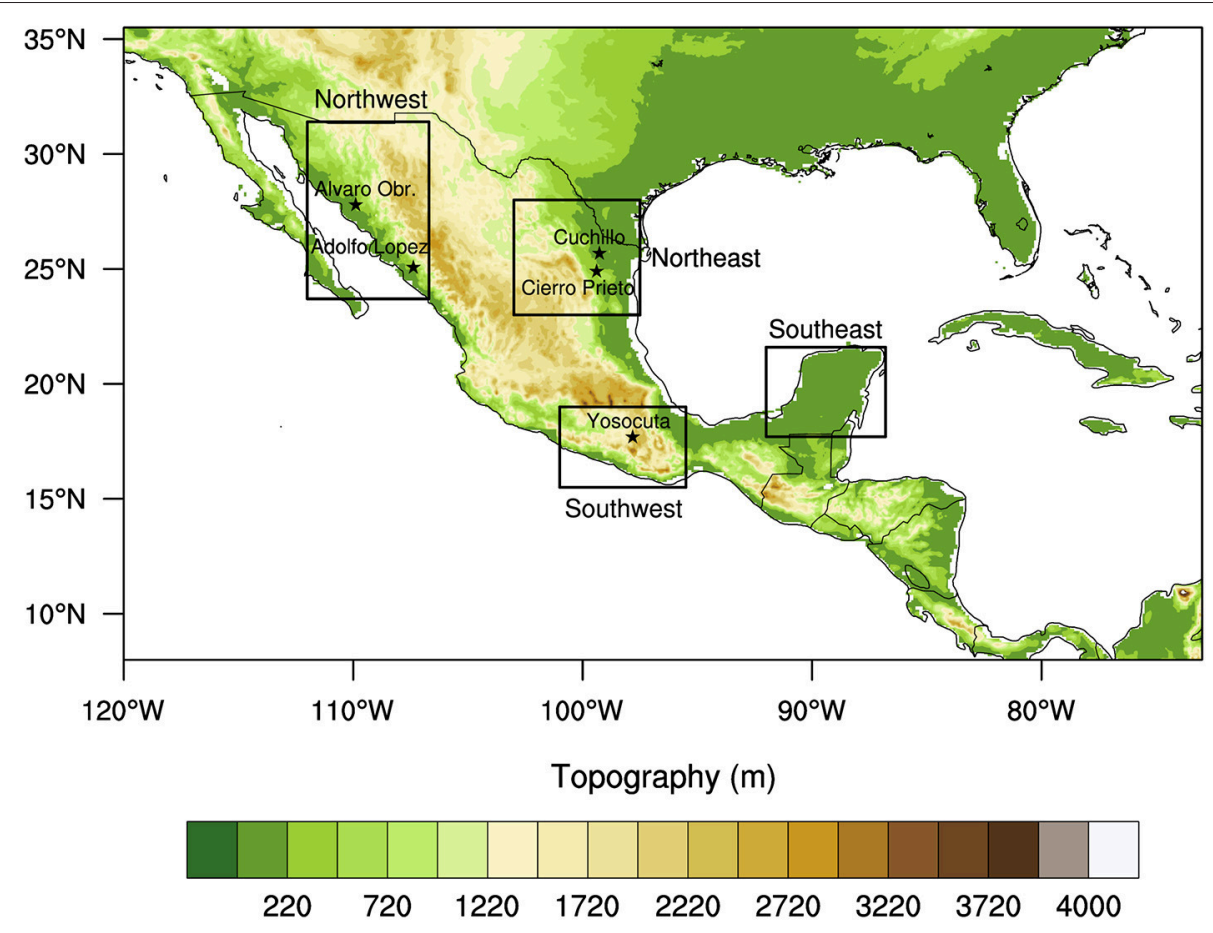

FIGURE 1 | Topography (m) and locations of water reservoirs (stars) over the four study regions: northwest, northeast, southeast and southwest of Mexico.

southern part of the Baja California peninsula, precipitation may vary from 500 to $800 \mathrm{~mm} \mathrm{yr}^{-1}$. In recent decades, the number of TCs over the northeastern tropical Pacific, and around southern Baja California peninsula in particular, has risen, inducing a positive trend in rainfall (Figure 2). Rain gauge data in southern Baja peninsula confirms the occurrence of intense precipitation when a TC is close by, as indicated in the HURDAT database. Anomalously wet years are usually related to the occurrence of one or two TCs in around the southern tip of the Baja peninsula ( $\mathrm{r} \approx 0.43$ at a $97 \%$ level of confidence). The reports of TCs making landfall over this region were analyzed together with the extreme precipitation captured by the surface stations during the 1941-2010 period. The increase in extreme rainfall could be only explained based on the rise of TCs that affect the Baja California Peninsula, since they are the only atmospheric systems that produce extreme precipitation during summer. In this sense, the uncertainty associated with missing TCs before the pre-satellite era decreases.

The TC contribution to seasonally accumulated precipitation is more relevant in arid-semiarid regions, as well as southern coastal regions (Figure 3). Most stations of northwestern and northeastern Mexico correspond to semiarid regions and there, TCs may contribute up to $40 \%$ of the annual precipitation in northwestern Mexico and up to $60 \%$ in the Baja California peninsula. The contribution depends on the number of TCs per season, but also on the dominant trajectories of these systems. In general, landfalling TCs or TCs sufficiently close to the coast affect these regions during the lifespan of these systems.
In relatively dry regions, where rainfall is generally less than $300 \mathrm{~mm} \mathrm{yr}^{-1}$, as in most of the northern Mexico and southwestern US, TCs may determine wet years. In the tropical regions, where precipitation is more than $1,000 \mathrm{~mm} \mathrm{yr}^{-1}$ on average, the rainfall contribution of a TC is less significant in annual precipitation. TCs produce and induce precipitation by means of moisture fluxes and by reducing the subsidence effect over the subtropical regions. Even when atmospheric moisture fluxes from the IAS or the TEP reach the arid and semiarid regions of northern Mexico, the intense subsidence and atmospheric stability at those latitudes reduces the chances of deep convection. When TCs approach, atmospheric stability diminishes and upward vertical motions develop to induce tropical convection. This effect is observed in the eastern Caribbean where TCs reduce atmospheric stability, causing intense ascending motion that results in deep convection and intense precipitation.

In summary, over the tropical Americas, the contribution of TCs to summer rainfall may be more than $40 \%$ in regions where the precipitation is less than $500 \mathrm{~mm} \mathrm{yr}^{-1}$, while it may be less than $30 \%$ in places where the summer rainfall is more than $700 \mathrm{~mm} \mathrm{yr}^{-1}$. In inland regions, such as the Mexican plateau or the central northern Mexico plateau, surrounded by the western and eastern Sierra Madre mountain ranges, the TC contribution to precipitation is meager, with less than $10 \%$ of the annual accumulated rainfall, because these tropical systems weaken after reaching the coastal regions.

TC activity is frequently modulated by modes of low frequency climate variability. For instance, TCs over the IAS are more 


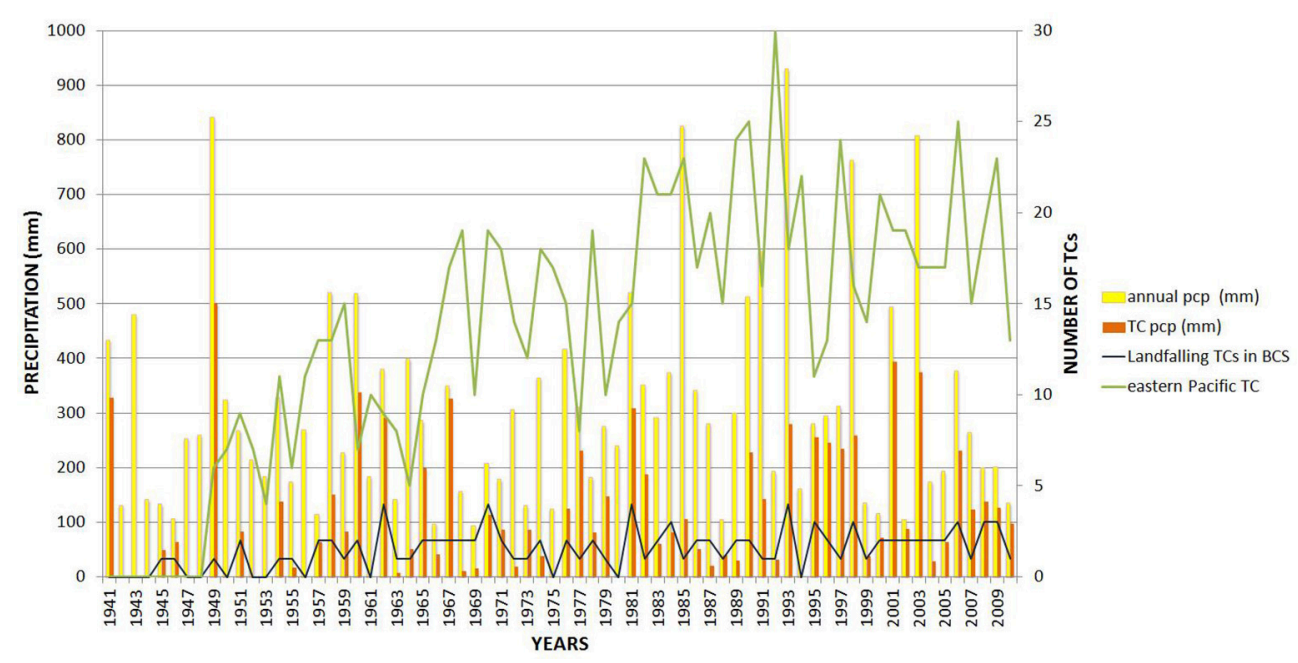

FIGURE 2 | Annual summer precipitation ( $\mathrm{mm}$ ) over the southern part of the Baja California peninsula (yellow bars) and the estimated contribution of tropical cyclones (TCs) to precipitation in the region (red bar). Number of TCs in the eastern tropical Pacific (green line) and number of TCs that affected the southern part of the Baja peninsula (black line) between 1941 and 2010.

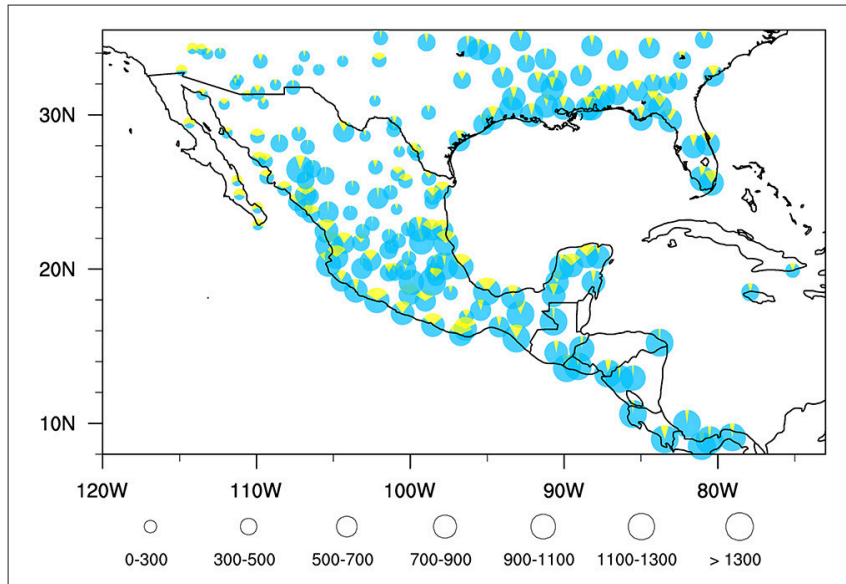

FIGURE 3 | Average annual rainfall (mm) (blue circles) for the 1979-2013 period, at stations where TCs have a contribution (yellow area) to the total precipitation. The circle size represents the amount of annual summer rainfall.

frequent under La Niña conditions (Bell and Chelliah, 2006), and consequently, they tend to induce a positive anomaly in precipitation over the continental regions of the tropical North America. The number of TCs over the IAS is larger during La Niña years as well as the number of days when TCs induce precipitation in a region. On the contrary, during $\mathrm{El}$ Niño years, there are less TCs over the IAS, and the number of TCs that induce precipitation over land is less as well. Over the northeastern tropical Pacific, the modulation of TC activity by ENSO (Figure 4A) is not as clear as over the IAS (Figure 4B). Considering the critical threshold distance from the coast $(500 \mathrm{~km})$, the mean number of days that TCs affect the coastal zone of northwestern or northeastern Mexico is around 2 days, and their contribution to annual precipitation is from $\sim 100$ to $250 \mathrm{~mm}$ (Figures 4 A,B). The TC activity, modulated by ENSO, may result in a weak contribution to annual precipitation.

In recent decades, there is a significant positive trend (97\% level of confidence) in TC activity over the TEP that is leading to more extreme precipitation events over the Mexican Pacific coast (Figure 2). The TEP TCs seldom last more than 1 day, but the number of systems and days of nearby TC activity are larger when compared to the other regions. TCs that affect the southwestern part of Mexico have a typical contribution to annual rainfall from 100 to $200 \mathrm{~mm}$ on average (Figure 4C). The southeast of Mexico and northern Central America are also affected by the Caribbean TCs, which on average, have a contribution of

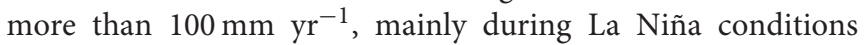
(Figure 4D). The interannual variations on such contribution to precipitation are more evident over the IAS (Kossin et al., 2010) than over the TEP (Camargo et al., 2008), essentially because of the ENSO modulation.

The TC contribution to annual rainfall may be examined in terms of the dominant trajectories of the systems, which may lead to further explain climate variability at a regional scale including these tropical transients. For the 1979-2009 period, a total of 264 TCs were analyzed by means of the CCT scheme. Over the Atlantic ocean, the CCT analysis showed that 13.2\% (35) of the TCs had straight trajectories, grouped in the IAS-A cluster (Figure 5A), that affected the Yucatan Peninsula and the northeastern part of Mexico; 36.7\% (97) had curved tracks that moved from the tropical central Atlantic into the eastern part of the USA, and were grouped in the IAS-B cluster (Figure 5B). The IAS-C cluster represents $30.7 \%$ (81) of TCs over the IAS, the corresponding trajectories were erratic, short-term life, and mainly impacted the central northern part of the Gulf of Mexico (Figure 5C). Finally, 19.3\% (51) of the TCs had a straightcurved trajectory over the Caribbean Sea and the northern part of the Gulf of Mexico, and were grouped in the IAS-D cluster 

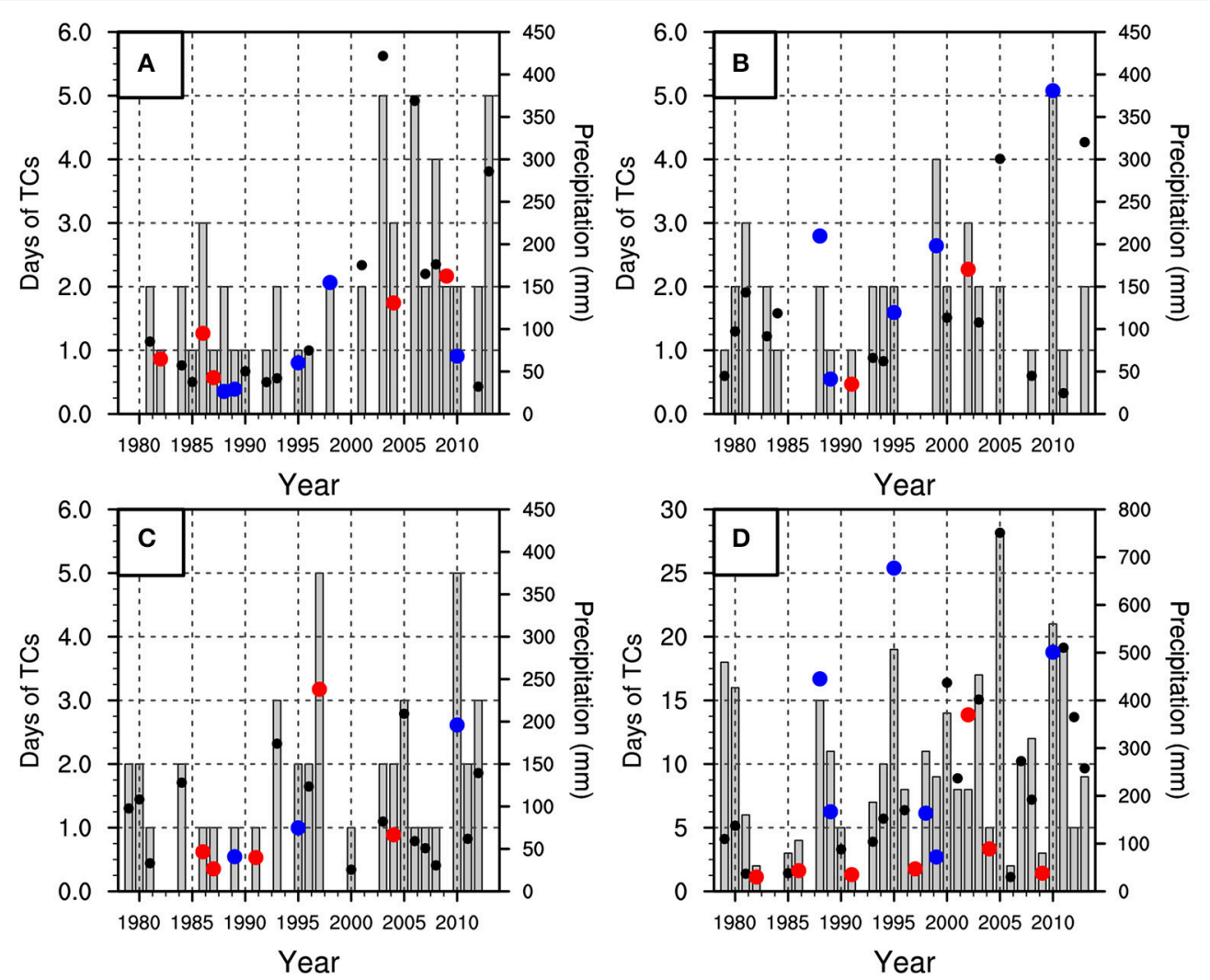

FIGURE 4 | Precipitation produced by tropical cyclones (TCs) (circles) and number of days (gray bars) when TCs affect: (A) northwest, (B) northeast, (C) southwest, and (D) southeast of Mexico and northern Central America for the 1979-2013 period. The red (blue) circles correspond to El Niño (La Niña) years and the black circles represent years defined as neutral conditions.

(Figure 5D). Around $40 \%$ of the IAS-A and IAS-D clusters were intense hurricanes (category 3,4 , and 5). $75 \%$ of TCs from the IAS-A cluster had a lifespan of up to 10 days. $75 \%$ of IAS-D cluster lasted up to 12 days, which makes them the longest lasting cluster of the IAS. Most of the TCs in the IAS-B and IAS-C clusters correspond to tropical storms (63 and 50\%, respectively).

Based on daily gridded precipitation data, the IAS and TEP TC cluster contribution to climatological summer precipitation was estimated for years when TCs were active in a particular cluster (Figures 5, 6). For the IAS-A cluster, the most affected regions by TC precipitation correspond to the states of the Yucatan peninsula and the eastern coastal states of Mexico, adjacent to the Gulf of Mexico (Figure 5A). TCs in cluster IAS-B mainly affected the eastern coast of the US (Figure 5B), while TCs in cluster $\mathrm{C}$ had an impact on the southeastern US states, close to the northern part of the Gulf of Mexico (Figure 5C). TCs in the IAS-D cluster mainly affected the Greater Antilles and parts of northern Central America and the Yucatan peninsula (Figure 5D).

The TEP clusters are not as contrasting as those in the IAS. Those that affected the Pacific coast of Central America and Mexico follow a more meridional trajectory than those that had a minimum contribution over continental regions and moved more zonally (Figure 6). During the 1979-2009 period, there were 549 TCs in the TEP: 22.8\% (125) affected the Baja California peninsula (TEP-A; Figure 6A); 13.1\% (72) of the systems had a long, almost zonal tracks (TEP-B), that affected only the southwestern states of Mexico (Figure 6B); cluster TEP-C only had $10.2 \%$ (52) of all the TCs in the region and had a trajectory parallel to the western Mexican coast. This kind of tracks moves away from Mexico as the TCs move northwestwards (Figure 6C). Finally, 53.9\% (296) of all the TCs are grouped in TEP-D cluster, distant from the continental region and consequently, with a meager contribution to summer precipitation in Mexico or Central America (Figure 6D). TEP-A and TEP-D clusters mainly correspond to tropical storms (49 and 45\%, respectively).

The cluster TEP-B includes the most intense hurricanes in the basin. In terms of their role as precipitation contributors over land, the TEP-A is the most important contributor to rainfall over northwestern Mexico. On average, the TEP-A contribution to the mean annual summer precipitation may be up to $30 \%$ of the seasonally accumulated rainfall, particularly in semiarid regions, where summer precipitation is less than $400 \mathrm{~mm} \mathrm{yr}^{-1}$. TCs from the TEP-B and TEP-C clusters contribute to rainfall only over the Pacific coast of southern Mexico.

ENSO modulates TC activity over the IAS. Cluster dominance under El Niño or La Niña conditions was examined. The 


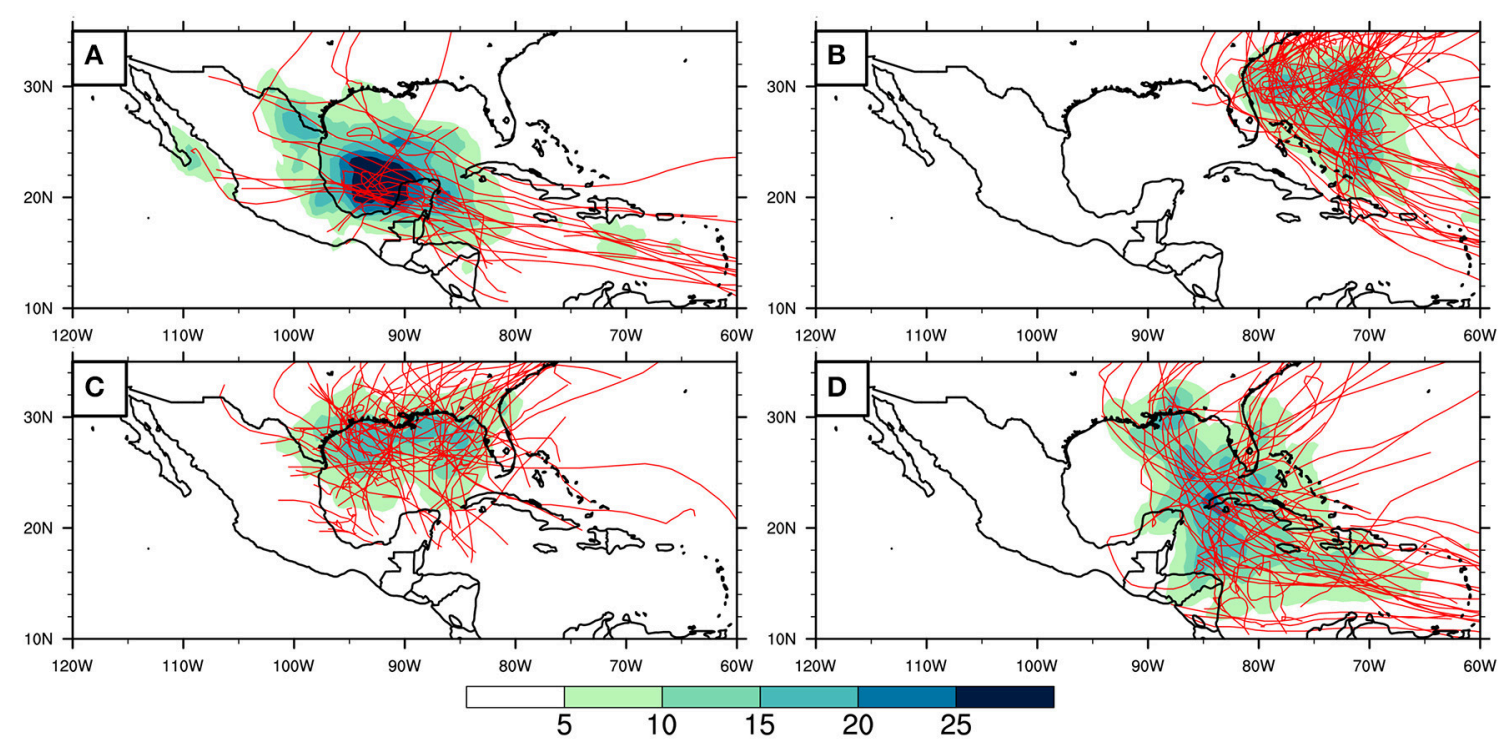

FIGURE 5 | Contribution (\%) of cluster (A) IAS-A, (B) IAS-B, (C) IAS-C, and (D) IAS-D to summer rainfall (shading) over the Intra Americas Seas for the 1979-2009 period. Observed TC trajectories for each cluster are denoted by red lines.

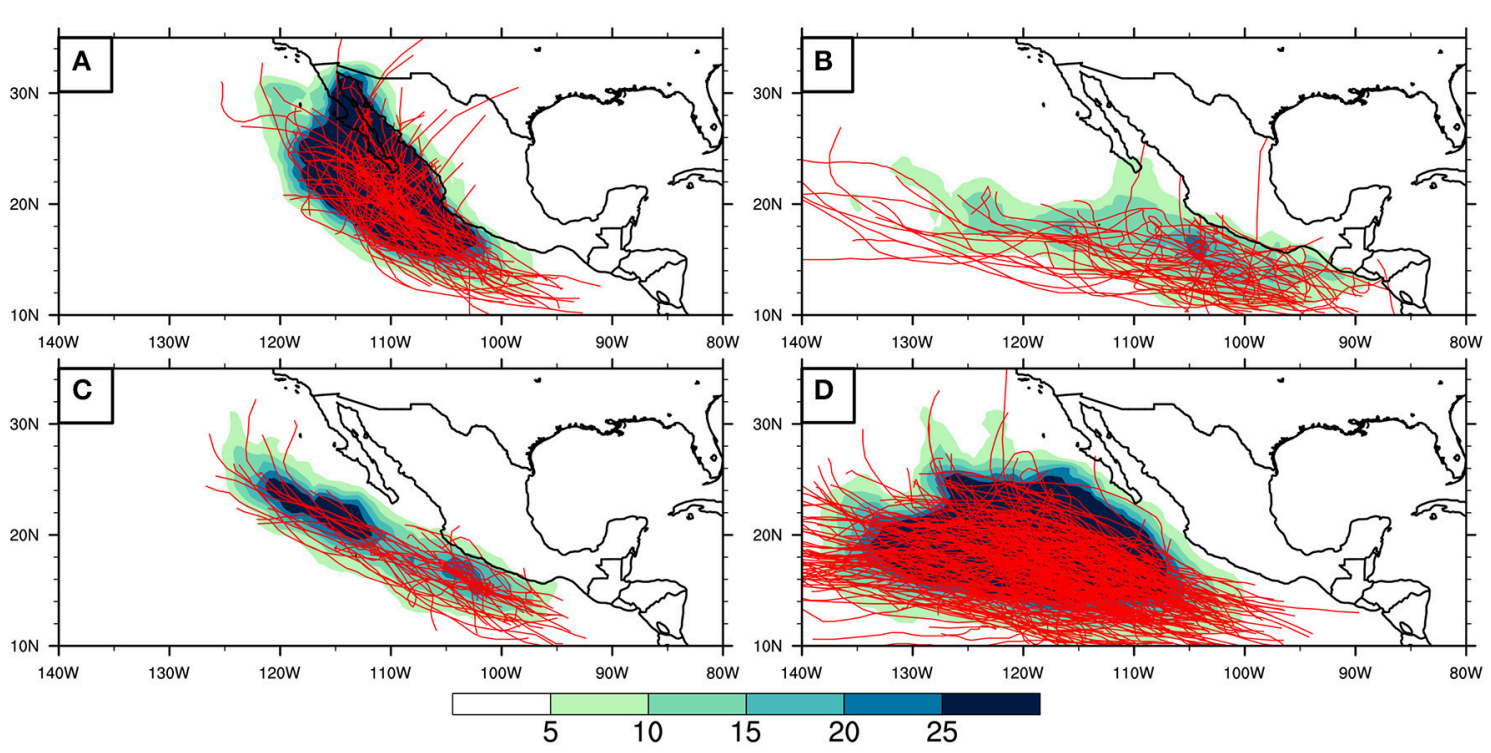

FIGURE 6 | Contribution (\%) of cluster (A) TEP-A, (B) TEP-B, (C) TEP-C, and (D) TEP-D to summer rainfall over the Tropical Eastern Pacific Ocean for the 1979-2009 period. Observed TC trajectories are denoted by red lines.

TC contribution to seasonal precipitation among clusters was contrasting from one cluster to another and between El Niño and La Niña conditions. El Niño (1982, 1987, 1991, 1997, 2002) and La Niña $(1988,1989,1995,1998,1999)$ years, and the rest of the years as neutral, resulted in statistically significant TC activity and variations in the TC contribution to seasonal precipitation. Clusters IAS-A, IAS-C and IAS-D are less active during El Niño years than during La Niña conditions (statistically significant at 99\% level of confidence and consistent with Kossin et al., 2010). For the TEP, only cluster TEP-B appears to be affected by El Niño conditions (statistically significant at $97.5 \%$ level of confidence and consistent with Camargo et al., 2008).

The TC activity and the type of trajectories exhibit large interannual and interdecadal variability over the IAS (Figure 7A) and over the TEP (Figure 7B). For instance, the summer of 1997 corresponded to El Niño conditions and only 4 TCs over the region occurred, mainly from cluster IAS-B, which does not contribute to seasonal precipitation in Mexico (Figure 7A). The summer of 1997 was particularly dry in central southern Mexico and Central America (Figure 8B). The lack of TCs 

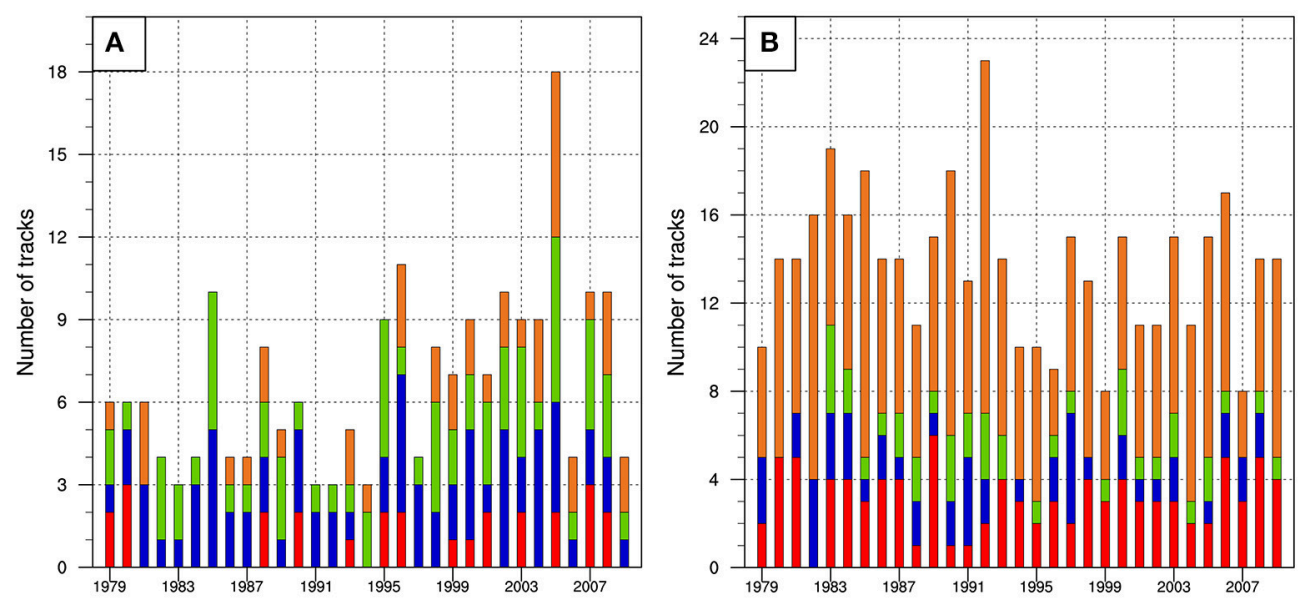

FIGURE 7 | Yearly number of TCs over (A) the Intra Americas Seas and (B) the Tropical Eastern Pacific for the 1979-2009 period. The partial contribution of clusters $\mathrm{A}$ (red), B (blue), C (green), and D (orange) is represented by the length of the bar.
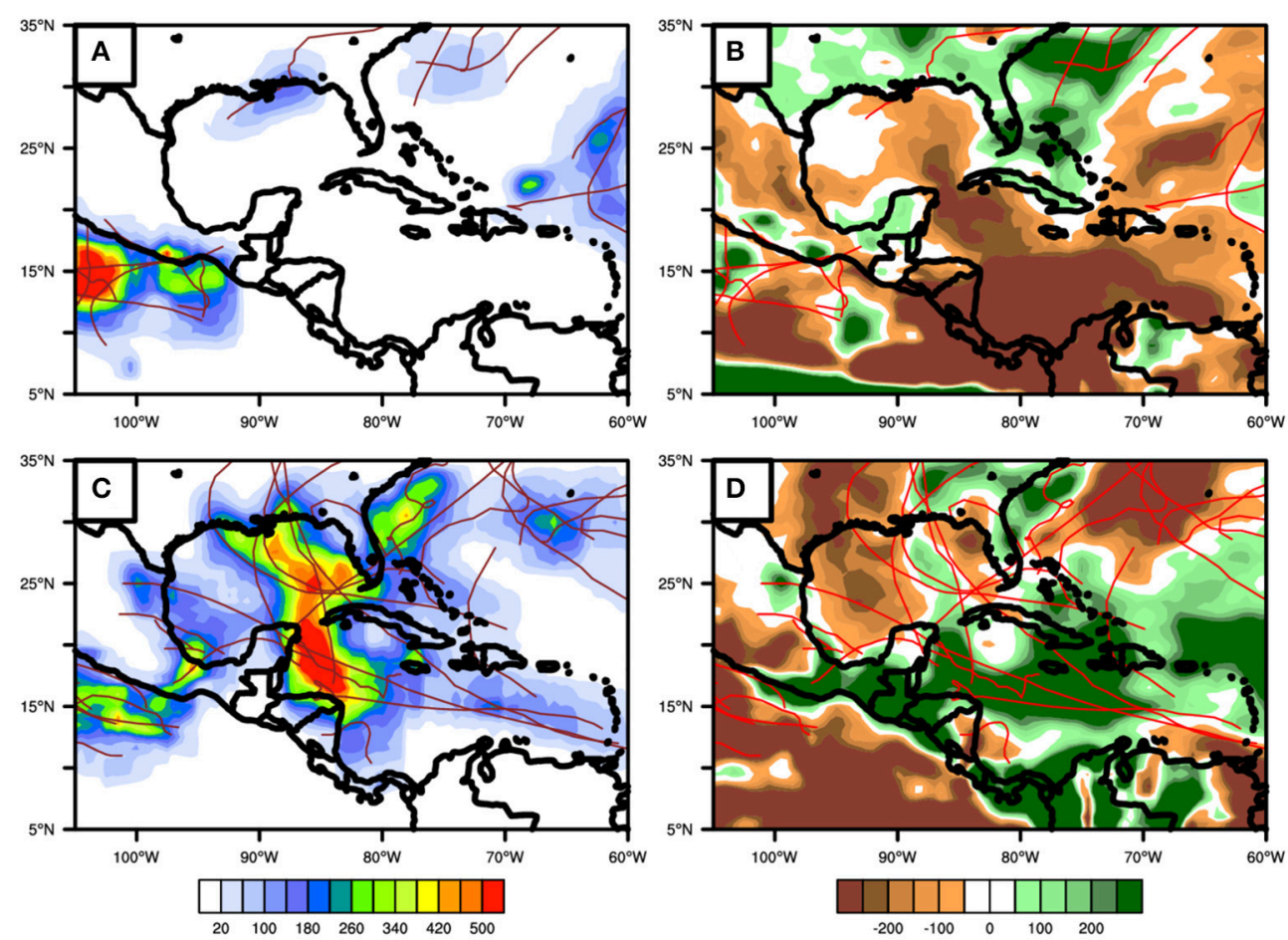

FIGURE 8 | (A) TC contribution to summer precipitation (mm) during 1997 and (B) the corresponding summer precipitation anomalies (mm) for that summer season, a relatively TC inactive period over IAS. (C) TC contribution to summer precipitation ( $\mathrm{mm}$ ) during 2005 and (D) the corresponding summer precipitation anomalies $(\mathrm{mm})$ for that summer season, a highly active TC period over IAS. Observed TC tracks are denoted by red lines.

over these regions along with enhanced subsidence, less easterly waves than average, and a southerly displaced Inter Tropical Convergence Zone (ITCZ) over the eastern Pacific contributed to this extremely dry condition (Magaña et al., 2003). In regions where some TC trajectories (cluster IAS-B and IAS-C) are observed, a positive precipitation anomaly is observed (Figure 8B). The IAS-B cluster appears to positively contribute to seasonal precipitation in 1997 off the eastern coast of the US, producing around $140 \mathrm{~mm}$ of rain (Figure 8A).

On the other hand, large TC activity over the IAS during 2005 was observed, with two TCs from the IAS-A cluster, four TCs from IAS-B, six TCs from IAS-C and six from IAS-D (Figure 7A), that contributed with approximately up to $260 \mathrm{~mm}$ over the northeastern Mexico and $560 \mathrm{~mm}$ over most of the 
Caribbean Sea and the Gulf of Mexico (Figure 8C). There is a close relationship between TC trajectories and their regional precipitation, which may add up to more than $500 \mathrm{~mm}$ in a few days (Figure 8C). It is clear though, that TCs are not the only source of precipitation in the tropical and subtropical North America, given that there are still negative seasonal precipitation anomalies even during a highly active 2005 TC season (Figure 8D).

The number of days under the influence of TCs is an important element to consider when analyzing the contribution of these topical systems to seasonal precipitation. For instance, when the number of TC days from cluster IAS-A is abovenormal, the precipitation anomalies over northeastern Mexico are mostly positive (Figure 9). Under strong El Niño conditions, TCs from cluster IAS-A are usually absent, as in 1982, 1987, and 1997 (Figure 7A), which results in negative precipitation anomalies over the northeastern part of Mexico.

However, the activity of cluster IAS-C can be normal under moderate El Niño conditions, as in 2002 or 2009, which may result in almost normal rainfall conditions in the northeast region (Figure 9). The correlation between the anomalies of regional precipitation and the anomalies of TC days for cluster IAS-A is 0.72 at $99.99 \%$ level of confidence.

When the TEP-A cluster is less active than normal, as in 1979, 1980, 1990, 1994, and 2005 under neutral ENSO conditions, a negative summer precipitation anomaly is more frequent over northwestern Mexico (Figure 10). TCs from cluster TEPA constitute important events to modulate seasonal precipitation in the North American monsoon region, as during the year of 2003 and 2006. The correlation between the anomalies of regional precipitation and the anomalies of TC days for cluster TEP-A is 0.82 at $99.99 \%$ level of confidence.

\section{Processes for TC Contribution or Inhibition to Regional Precipitation}

The mechanisms which favor or inhibit precipitation over the regions affected by the TC activity are related to changes in moisture fluxes (convergence and divergence), as in the ITCZ or the Caribbean Sea. The subtropical regions correspond to zones where moisture divergence at lower levels is strong. The IAS regions also experience the effects of subsidence that inhibit deep convection (Magaña and Caetano, 2005). Easterly waves and TCs are mechanisms that reduce atmospheric stability and allow the development of tropical convective activity over the oceanic subtropical regions. TC clusters induce zones where anomalous moisture convergence occurs. An example of such effect is presented for TCs from cluster IAS-B during the years $1984,1985,1989$, and 2006, when IAS-B activity is abovenormal. When the mean $700 \mathrm{hPa}$ circulation for the Northern Hemisphere summer (JJASO) is obtained, it is observed that moisture divergence dominates over the IAS, with the presence of a mean southeasterly flow at the TC steering level (Figure 11A). However, when TCs of a particular IAS cluster are present, the situation may vary significantly due to changes in the mean atmospheric circulation and the moisture flux divergence. For instance, when TCs from IAS-B cluster are present, moisture

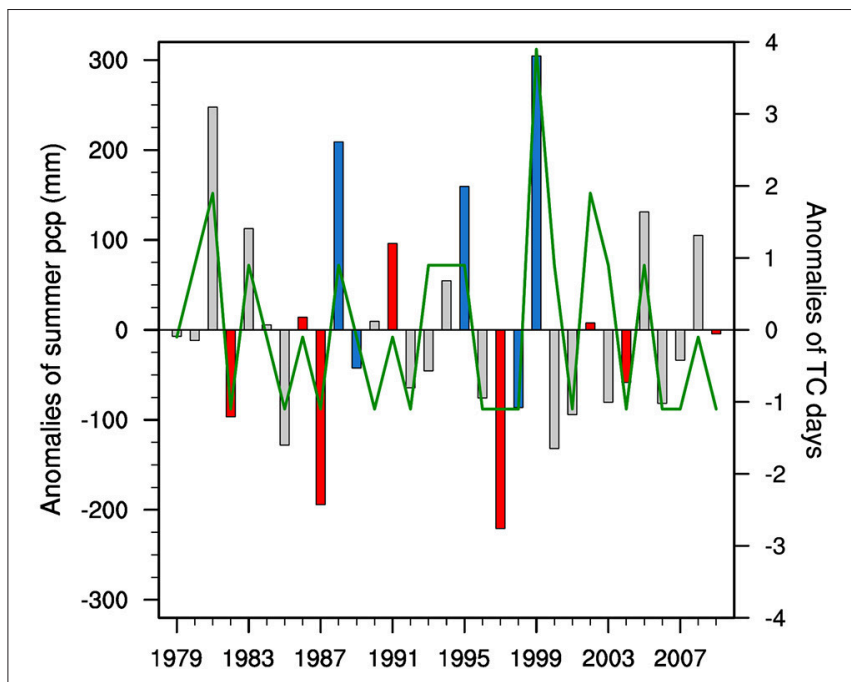

FIGURE 9 | Time series of summer (JJASO) average precipitation anomalies $(\mathrm{mm})$ in the northeastern Mexico for the 1979-2009 period. The red (blue) bars correspond to El Niño (La Niña) years and the gray bars represent years defined as neutral conditions. The green line represents the anomalies in the number of TC days for cluster IAS-A.

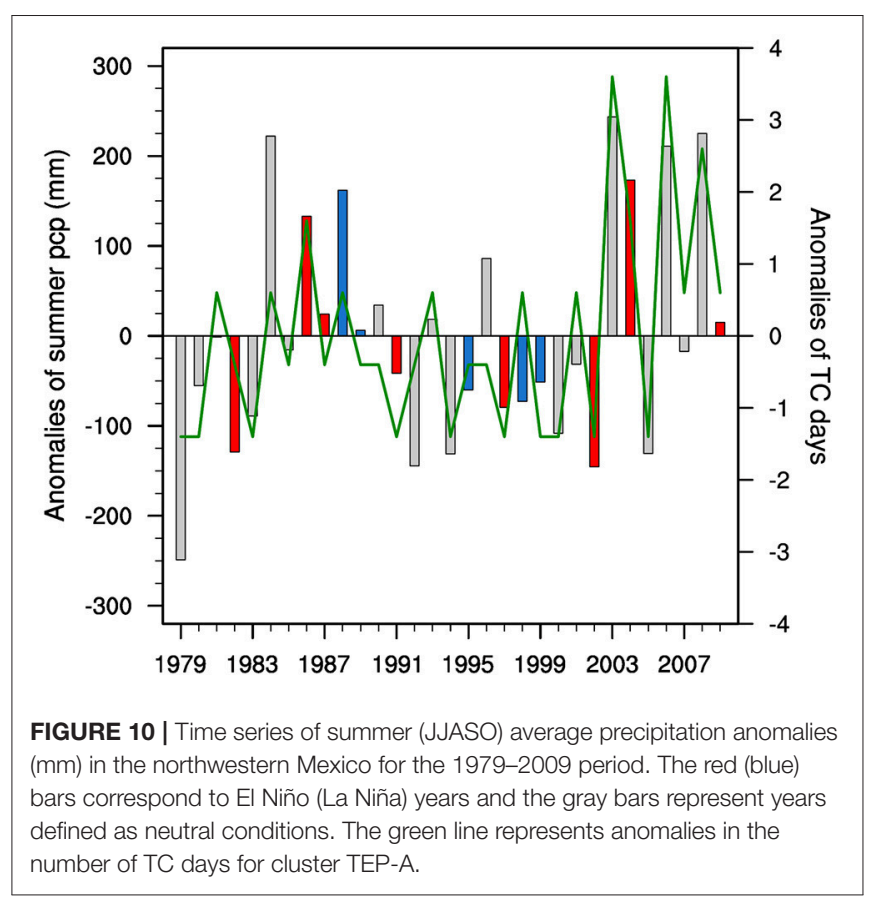

flux convergence is large over off the southeastern US, while divergence is enhanced over the Caribbean Sea (Figure 11B). In other words, the presence of TCs in a region induce moisture flux convergence, as well as moisture flux divergence in surrounding regions inhibiting tropical convection an reducing the amount of seasonal rainfall.

Over the TEP, the ITCZ is a region of intense moisture convergence. Off the Baja California peninsula, moisture 


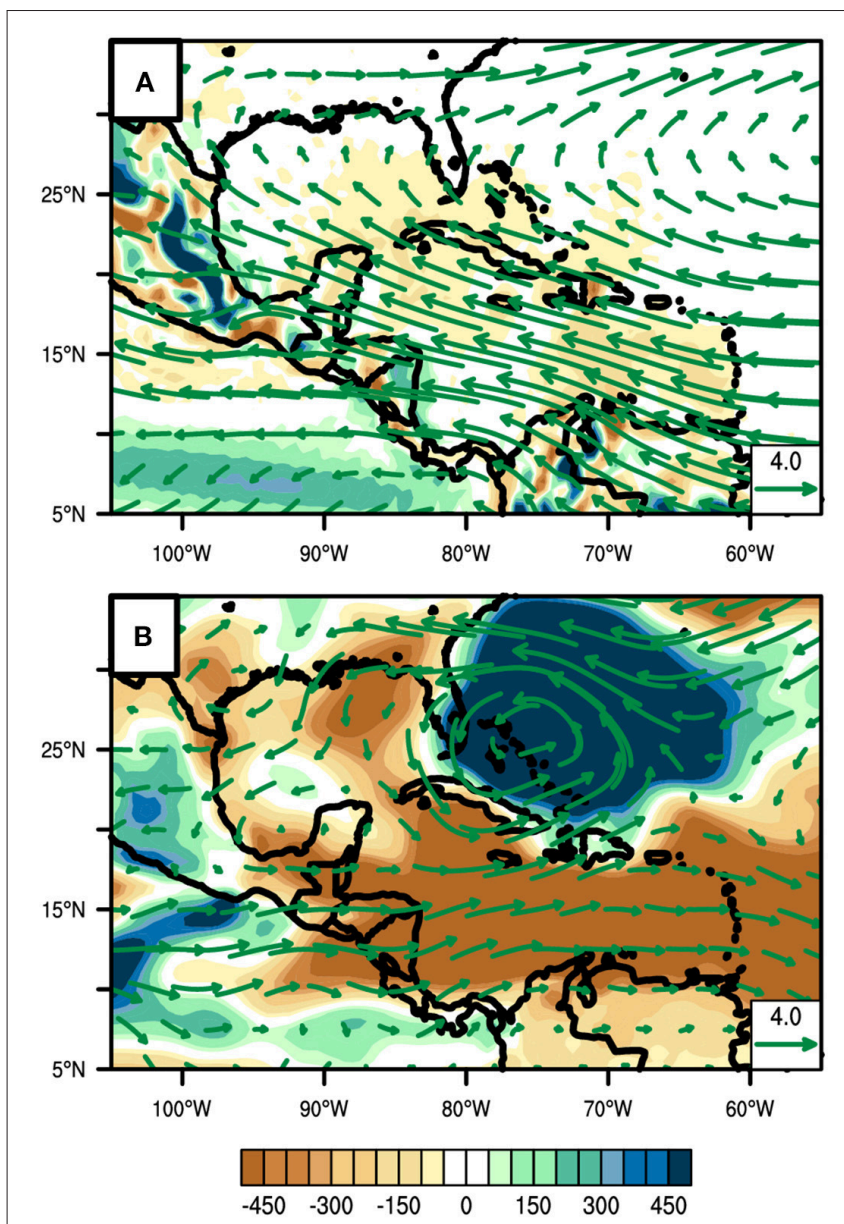

FIGURE 11 | (A) $700 \mathrm{hPa}$ wind field (m/s) (green vectors) and water vapor flux convergence accumulation $\left(\mathrm{kg} / \mathrm{m}^{2}\right)$, for the entire atmosphere considered as a single layer (shaded), mean state over the IAS for JJASO and (B) Average anomalies during days when IAS-B cluster was active during 1984, 1985, 1989 , and 2006.

divergence dominates during the summer months (Figure 12A). The TEP-D is active and TEP-A cluster is almost inactive, moisture divergence over the northwestern states of Mexico is enhanced (Figure 12B), which induces negative anomalies of precipitation. The spatial pattern of the anomalous moisture convergence tends to coincide with the regions of anomalous cyclonic circulations associated with enhanced TEP-D cluster activity, around $17 \mathrm{~N}, 120 \mathrm{~W}$.

\section{Mean Atmospheric Circulations at the TC Steering Level}

TC trajectories are the result of complex interactions between a number of internal and external influences. The preferred TC trajectory mainly depends on the location where the system forms and the mean quasi-stationary circulations at the steering level. Atmospheric circulations at $700 \mathrm{hPa}$ may be an adequate approximation for the steering level, since the mean seasonal circulations include the effect of the TC, and reflect their presence
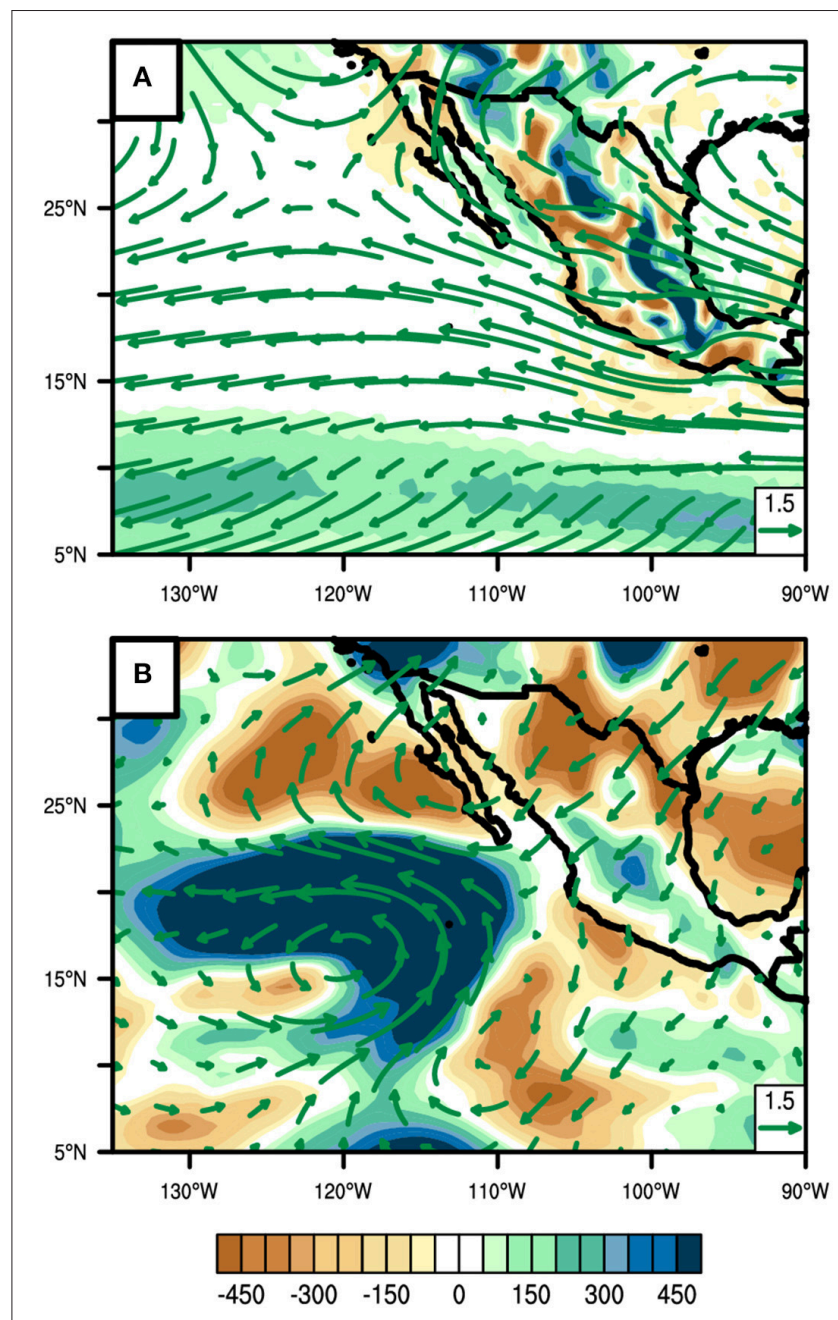

FIGURE 12 | (A) $700 \mathrm{hPa}$ wind field (m/s) (green vectors) and water vapor flux convergence accumulation $\left(\mathrm{kg} / \mathrm{m}^{2}\right)$, for the entire atmosphere considered as a single layer (shaded), mean state over the TEP for JJASO and (B) Average anomalies during days when TEP-D cluster was active during 1980, 1985, 1990, and 1994.

in the circulation in particular regions. However, they also show the mean background flow in which the TCs move, such as subtropical large-scale circulations, hardly affected by the TC passage. The mean southeast-northwest trajectory for a TC is mainly determined by the beta effect (Adem, 1956), but the flow over the Atlantic basin, given by the presence of the North Atlantic Subtropical High (NASH), plays a major role in defining the preferred trajectory followed by TCs (Lenggenhager, 2013), but its variations may determine the frequency of a particular TC cluster. For instance, for the IAS-A cluster, the NASH extends zonally at around $30^{\circ} \mathrm{N}$, and the dominant circulation at the steering level extends from the Caribbean Sea into the Yucatan peninsula and the coastal regions of the western Gulf of Mexico (Figure 13A). For the IAS-B cluster, the mean circulation of the steering level includes the NASH that extends to the eastern coast of the USA allowing the TCs to recurve around this region. 

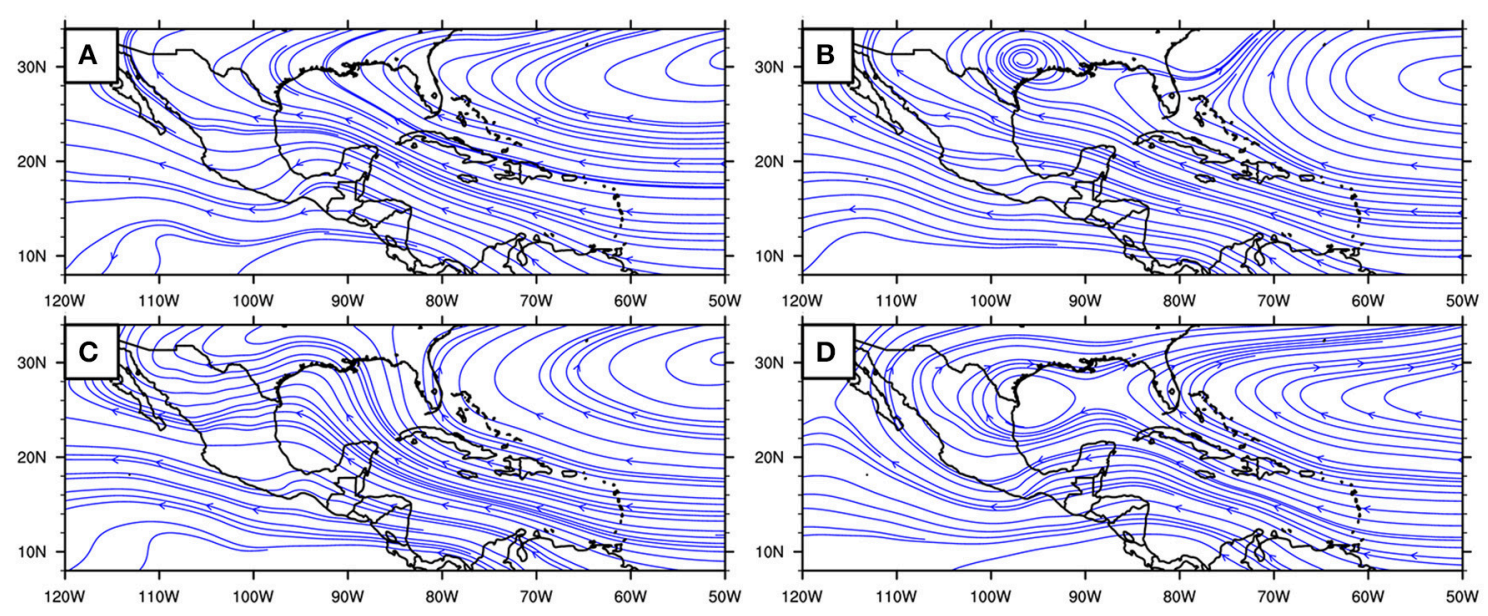

FIGURE 13 | Mean steering (streamlines at $700 \mathrm{hPa}$ ) flow of clusters over the Intra-Americas Sea during the 1979-2009 period for: (A) IAS-A, (B) IAS-B, (C) IAS-C, and (D) IAS-D.

An anticyclonic circulation over Texas also seems to prevent these systems from moving into the southern USA (Figure 13B). Clusters IAS-C and IAS-D, also show circulations over the IAS (Figures 13C,D) that determine the preferred TC trajectories.

For the TEP region, the trajectories largely depend on whether the wind off the Pacific coast of Mexico has a strong meridional component or not (Figure 14). The more zonal the flow, the more distant the TCs move from the continental region. For instance, for the TEP-A cluster, the mean flow at the $700 \mathrm{hPa}$ steering level has a well-defined circulation into the Gulf of California that increases the chances of TCs to move inland into the northwestern Mexico (Figure 14A). For clusters TEP-B and TEP-C, the steering level flow (Figures 14B,C) show that the circulation is intense close to the southern coast of Mexico and then deflects into the central Pacific, preventing TCs from reaching northwestern Mexico, as observed in the corresponding clusters. The flow tends to be more zonal for the TEP-D cluster, which determines more zonal trajectories into the central Pacific and off the coast of the Mexican Pacific (Figure 14D).

If the mean flow for a summer season were estimated, it would be possible to determine the preferred TC cluster or TC dominant trajectories. This is certainly a difficult task, but should be pursued if the potential impacts of TCs in regional precipitation are projected for instance, for water management purposes.

\section{Impact of TCs on Water Reservoirs}

The TC impact in water reservoir levels may be analyzed by using data of the dam levels prepared by the Mexican National Water Commission (CONAGUA). The analysis of the impact of TC on water levels was done for the Adolfo Lopez Mateos and the Alvaro Obregon dams, which are located in the northwestern region of Mexico and have a Maximum Operating Storage Capacity (MOSC) of 3086.1 and 2989.2 millions of cubic meters $(\mathrm{mcm})$, respectively. For the northeastern region of Mexico, El Cuchillo and Cerro Prieto dams, with MOSCs of 1123.14 and $300 \mathrm{mcm}$, were examined. Finally, Yosocuta located in the southwestern part of Mexico, with a MOSC of only $46.8 \mathrm{mcm}$, was used as an example.

The Net Volume Index (NVI) was used to assess the contribution of TCs to the water stored in these reservoirs. Following Sisto et al. (2015), the NVI can be expressed as:

$$
\text { NVI }(\%)=\frac{\text { volume stored }- \text { minimum operating capacity }}{\text { Maximum Operating Capacity }}
$$

The NVI difference between months when TCs produced intense rains and runoff and months without tropical cyclone activity over the regions served to estimate the impact of TCs on the water availability of the previously mentioned dams.

TCs produce extreme precipitation, which could significantly change stored water levels. The impacts; however, are more important in the water reservoirs located in the north. TCs from the TEP-A cluster can raise the water level from 10 up to $70 \%$ in the reservoirs situated in the northwestern region (Figure 15). TCs of the IAS-A and IAS-C clusters can significantly change the NVI in reservoirs located in the northeastern Mexico, from values of $\sim 30 \%$ to values of $\sim 100 \%$. During the $2010-$ 2013 drought period, the water levels of reservoirs located in the northeastern Mexico dramatically diminished due to an increase in water demands and a strong meteorological drought. The northeastern Mexico water crisis was slightly alleviated by two TC events: hurricane Alex in 2010 (IAS-A), under La Niña conditions and Tropical Storm Ingrid in 2013 (IAS-C), under neutral conditions. They provided such enough water to reservoirs that a major catastrophe on water supply over that region was avoided (Sisto et al., 2015). Their contribution to water levels of the dams was independent of their intensity.

In the southern regions of Mexico, the NVI of water reservoirs is barely noticeable when TCs occur nearby. The impact of clusters TEP-B and TEP-C produce, on average, an increase of $10 \%$ in the water levels, given the relatively minor contribution of TCs to summer rainfall in these regions. 

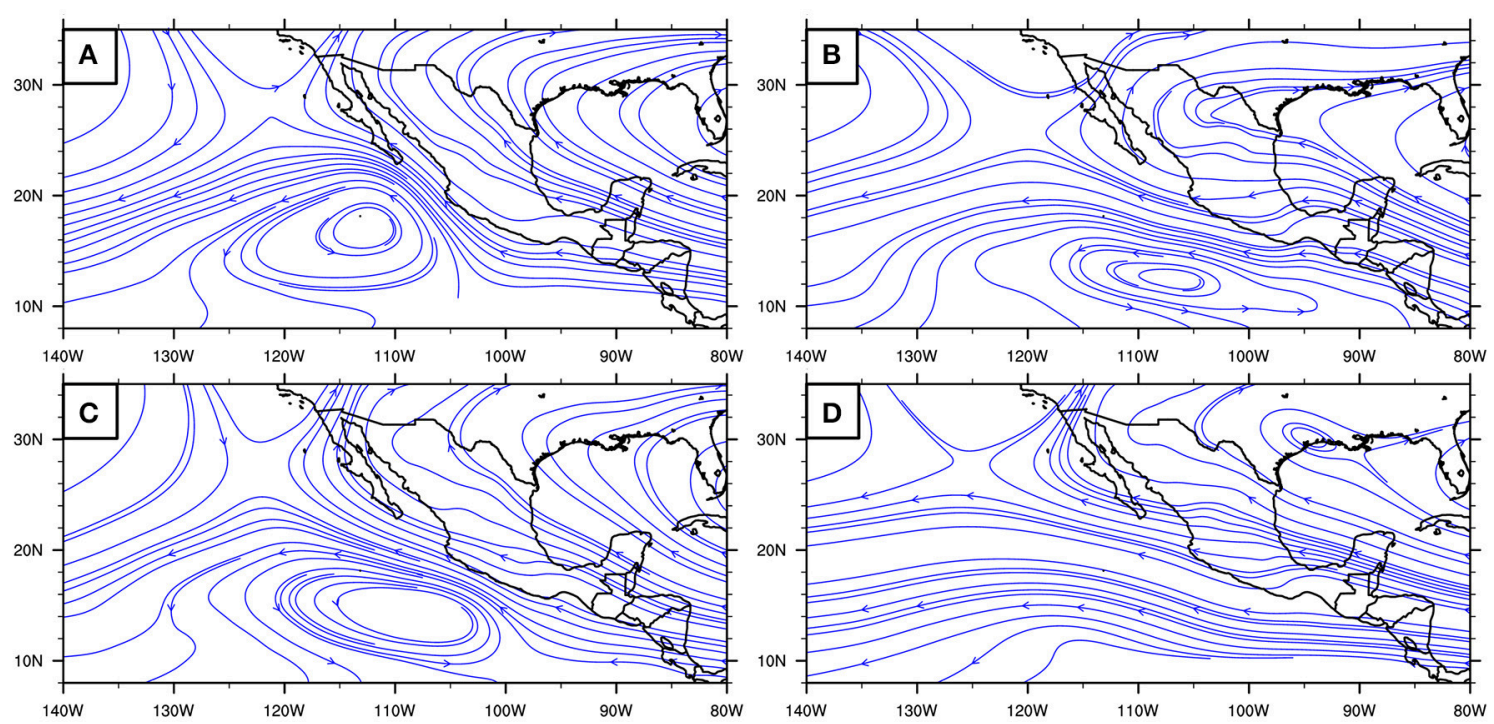

FIGURE 14 | Mean steering (streamlines at $700 \mathrm{hPa}$ ) flow of clusters over the Tropical Eastern Pacific during the 1979-2009 period for: (A) TEP-A, (B) TEP-B, (C) TEP-C, and (D) TEP-D.

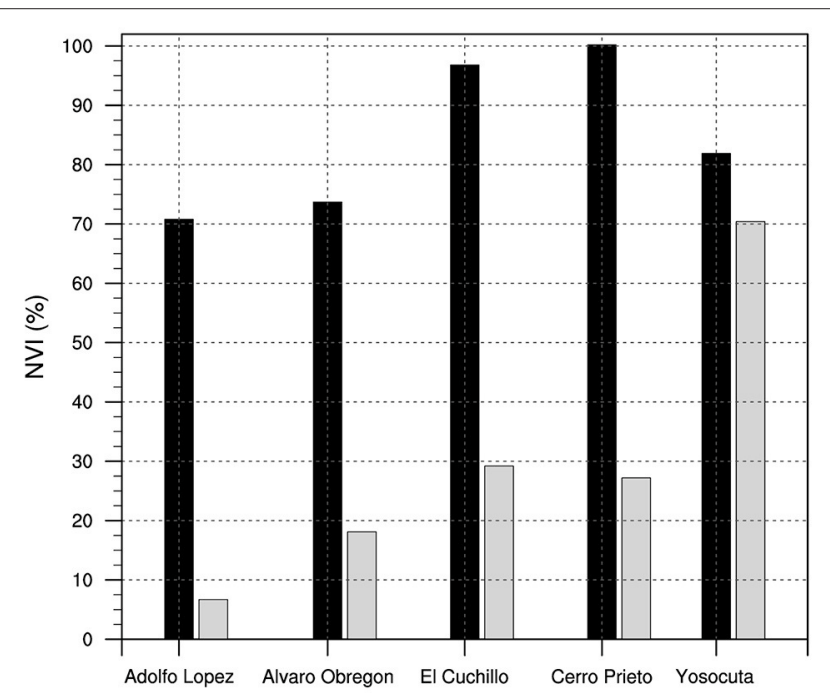

FIGURE 15 | Change (\%) of Net Volume Index (NVI) of water reservoirs during months of tropical cyclones inducing precipitation in the region (dark bars) and without TCs influence (light bars) for the 1979-2013 period.

\section{DISCUSSION AND CONCLUSIONS}

TCs are recognized as key contributors to summer precipitation in most tropical regions. Their role in water balances is crucial in semi-arid regions as in northern Mexico, as they may provide up to $50 \%$ of the seasonal precipitation in some regions. Various studies have estimated that the contribution of TCs to the accumulated annual or seasonal precipitation may be from 10 to $50 \%$, which makes them key elements of the water balances in countries like Mexico. However, variations in TCs activity are part of the interannual climate variability, leading to positive and negative anomalies in precipitation. In other words, some of the wettest or driest years for some regions may depend on the characteristic (number and trajectories) of the TC season. This dual role of TCs in modulating seasonally accumulated precipitation is rarely considered in climate predictions or outlooks.

In the present study, these opposite effects of TCs have been analyzed, for TCs in the IAS and tropical eastern Pacific for the 1979-2009 period. The use of a threshold-distance of $5^{\circ}$ captured adequately the rainfall produced by TCs. The main elements to consider in the estimates of the TC contribution to seasonal rainfall are the location and the trajectory, including number of days that the system affects a region. Details of individual TC size and shape add limited value to the considerations on the radius of influence of the TC (Xu et al., 2017). TCs from a particular trajectory cluster affect precipitation by means of enhancing or reducing moisture flux convergence or divergence. TCs that approach northern Mexico may cause significant increases in water availability thanks to 1 or 2 days of intense rainfall, as long as the TC is close enough to the shoreline. Nevertheless, years of above-normal or normal TC activity, either over IAS or TEP, may not necessarily mean above-normal or normal expected precipitation at the regional level. This will depend on TC activity for specific trajectories (clusters), particularly for the northeastern or northwestern Mexico. Even more, the absence of certain type of TC track may lead to significant negative anomalies of precipitation for some regions.

An estimate of the so-called TC mean steering level, say at $700 \mathrm{hPa}$, may be of great benefit to outlook the potential effect of TCs of a particular trajectory over a continental region. The relationship between the mean quasi-stationary circulations and 
ENSO conditions may serve to predict the mean flow at the 700 $\mathrm{hPa}$ and to consider if a TC may induce more or less precipitation. Several attempts to predict TC activity, not only in terms of number of systems, but also in terms of regions where their activity may be more frequent for a season, have been developed to have an estimate of the regions that may be affected, but not with the aim of including their effect on seasonal precipitation forecasts. If such type of predictions were created, they could serve to prepare water management plans, mainly for regions that largely depend on the effect of TCs to increase water availability, as the semiarid regions of the north of Mexico. The TC activity for the Atlantic and the Eastern Pacific has generally been diagnosed and forecasted using ENSO conditions (Klotzbach et al., 2011). In this sense, the oceanic forcing is the main modulator of the dominant seasonal atmospheric circulation patterns, which in fact lead to preferred trajectories of TCs at the steering level, for instance, $700 \mathrm{hPa}$.

At present, the effect of TCs in the hydrological cycle, of northern Mexico for instance, is missing in most seasonal forecasts produced by global climate models. At times, estimates of the impacts of TCs on seasonal precipitation have been developed, considering the forecasts of the number of TCs and intensity. However, the TC trajectory may be more relevant for rainfall predictions than the intensity of the system itself. The

\section{REFERENCES}

Adem, J. (1956). A series solution for the barotropic vorticity equation and its application in the study of atmospheric vortices. Tellus 8, 364-372. doi: 10.3402/tellusa.v8i3.9010

Aguilar-Benitez, I. (2011). Los Servicios del Agua en el Norte de México en Gestión, Manejo Financiero y Aspectos Ambientales. México: Ed. El Colef y El Colson.

Bell, G. D., and Chelliah, M. (2006). Leading tropical modes associated with interannual and multidecadal fluctuations in North Atlantic hurricane activity. J. Climate 19, 590-612. doi: 10.1175/JCLI3659.1

Breña-Naranjo, J. A., Pedrozo-Acuña, A., Pozos-Estrada, O., Jiménez-López, S. A., and López-López, M. R. (2015). The contribution of tropical cyclones to rainfall in Mexico. J. Phys. Chem. Earth. 83, 111-122. doi: 10.1016/j.pce.2015.05.011

Camargo, S. J., Robertson, A. W., Barnston, A. G., and Ghil, M. (2008). Clustering of Eastern North Pacific tropical cyclone tracks: ENSO and MJO effects. Geochem. Geophys. Geosyst. 9:Q06VQ05. doi: 10.1029/2007GC001861

Camargo, S. J., Sobel, A. H., Barnston, A. G., and Klotzbach, P. J. (2010). "Chapter XI: The influence of natural climate variability on tropical cyclones, and seasonal forecasts of tropical cyclone activity," in Global Perspectives on Tropical Cyclones from Science to Mitigation, 2nd Edn., World Scientific Series on Earth System Science in Asia, eds J. C. L. Chan and J. D. Kepert (Singapore: World Scientific Publishing Co. Pte. Ltd.), 325-360.

Cerveny, R. S., and Newman, L. E. (2000). Climatological relationship between tropical cyclones and rainfall. Mon. Weather Rev. 128, 3329-3336. doi: 10.1175/ 1520-0493(2000)128<3329:CRBTCA >2.0.CO;2

Dee, D. P., Uppala, S. M., Simmons, A. J., Berrisford, P., Poli, P., Kobayashi, S., et al. (2011). The ERA-Interim re-analysis: configuration and performance of the data assimilation system. Q. J. R. Meteorol. Soc. 137, 553-597. doi: $10.1002 /$ qj. 828

Díaz, S. C., Salinas-Zavala, C. A., and Hernández-Vázquez, S. (2008). Variability of rainfall from tropical cyclones in northwestern México and its relation to SOI and PDO. Atmósfera 21, 213-223.

Emanuel, K. A. (1997). Some aspects of hurricane inner-corner dynamics and energetic. J. Atmos. Sci. 54, 1014-1026. doi: 10.1175/15200469(1997)054<1014:SAOHIC>2.0.CO;2 present analysis may lead to develop forecast schemes of TC trajectories for the Americas that eventually result in rainfall estimates. For the time being, the empirical results of this analysis serve to emphasize the role of TCs in any projection of climate, or as a source of uncertainty in seasonal climate predictions or climate change scenarios. Future work should consider the role of large-scale forcing in determining preferred TC tracks and ensembles of scenarios on what their effect could be on seasonal climate at a regional scale.

\section{AUTHOR CONTRIBUTIONS}

CD and VM worked together to share and discuss ideas, how to prepare plots and writing. Each one contributed to this research by exploring data, making useful observations and developing new techniques for capturing tropical cyclone rainfall.

\section{ACKNOWLEDGMENTS}

CD was financially supported by CONACyT under the scholarship 41243. The present study has benefited from the financial support of projects INEGI-CONACyT 209932, and PAPIIT IN112717. The technical assistance of Gustavo Vázquez is appreciated.
Englehart, P. J., and Douglas, A. V. (2001). The role of eastern North Pacific tropical storms in the rainfall climatology of western Mexico. Int. J. Climatol. 21, 1357-1370. doi: 10.1002/joc.637

Gaffney, S. J. (2004). Probabilistic Curve-Aligned Clustering and Prediction with Regression Mixture Models. Ph.D. thesis, University of California, Irvine, CA.

Gutzler, D. S., Long, L. N., Schemm, J., Roy, S. B., Bosilovich, M., Collier, J. C., et al. (2009). Simulations of the 2004 North American monsoon: NAMAP2. J. Climate 22, 6716-6740. doi: 10.1175/2009JCLI3138.1

Hill, K. A., and Lackmann, G. M. (2009). Influence of environmental humidity on tropical cyclone size. Mon. Weather Rev. 137, 3294-3315. doi: 10.1175/2009MWR2679.1

Jáuregui, O. E. (2003). Climatology of landfalling hurricanes and tropical storms in Mexico. Atmósfera 16, 194-204.

Jiang, H., and Zipser, E. J. (2010). Contribution to the global precipitation from eight seasons of TRMM data: regional, seasonal and interannual variations. J. Clim. 23, 1526-1543. doi: 10.1175/2009JCLI3303.1

Klotzbach, P. J., Barnston, A., Bell, G., Camargo, S. J., Chan, J. C. L., Lea, A., et al. (2011). Seasonal Forecasting of Tropical Cyclones in Global Guide to Tropical Cyclone Forecasting, 2nd Edn., ed C. Guard. Geneva: World Meteorological Organization.

Kossin, J. P., Camargo, S. J., and Sitkowski, M. (2010). Climate modulation of North Atlantic hurricane tracks. J. Clim. 23, 3057-3076. doi: 10.1175/2010JCLI3497.1

Kubota, H., and Chan, J. C. L. (2009). Interdecadal variability of tropical cyclone landfall in the Philippines from 1902 to 2005. Geophys. Res. Lett. 36:L12802. doi: 10.1029/2009GL038108

Larson, J., Zhou, Y., and Higgins, R. W. (2005). Characteristics of landfalling tropical cyclones in the United States and Mexico: climatology and interannual variability. J. Clim. 18, 1247-1262. doi: 10.1175/JCLI3317.1

Lenggenhager, S. (2013). Tropical Cyclone Tracks and the Subtropical High Pressure System in the North-Atlantic in a 400-year Climate Simulation. Master's thesis, University of Bern, Bern.

Magaña, V. (2004). Los Impactos del Ni-o en México. Mexico: Universidad Nacional Autónoma de México and Secretaría de Gobernación. 
Magaña, V., and Caetano, E. (2005). Temporal evolution of summer convective activity over the Americas warm pools. Geophys. Res. Lett. 32:L02803. doi: 10.1029/2004GL021033

Magaña, V., and Neri, C. (2012). Cambio Climático y Sequías en México. Revista Ciencia de la Academia de Ciencias 63, 26-35.

Magaña, V., Vázquez, J. L., Pérez, J. L., and y Pérez, J. B. (2003). Impact of El Niño on precipitation in Mexico. Geofís. Int. 42, 313-330.

Méndez, M., and Magaña, V. (2010). Regional aspects of prolonged meteorological droughts over Mexico and Central America. J. Clim. 23, 1175-1188. doi: 10.1175/2009JCLI3080.1

Neri, C., and Magaña, V. (2016). Estimation of vulnerability and risk to meteorological drought in mexico. Weather Clim. Soc. 8, 95-110. doi: 10.1175/WCAS-D-15-0005.1

Pasch, R. J., and Roberts, D. P. (2006). Tropical Cyclone Report: Hurricane Stan. Miami, FL: National Hurricane Center, 1-12.

Rogers, E. B., Adler, R. F., and Pierce, H. F. (2000). Contribution to the North Pacific climatological rainfall as observed from satellites. J. App. Meteorol. 39, 1648-1678. doi: 10.1175/1520-0450(2000)039<1658:COTCTT $>2.0 . C O ; 2$

Shanko, D., and Chamberlain, P. (1998). The effects of the south-west Indian Ocean tropical cyclones on Ethiopian drought. Int. J. Climatol. 18, 1373-1388. doi: 10.1002/(SICI)1097-0088(1998100)18:12<1373::AIDJOC313>3.0.CO;2-K

Shephard, J. M., Grundstein, A., and Mote, T. L. (2007). Quantifying the contribution of tropical cyclones to extreme rainfall along the coastal southeastern United States. Geophys. Res. Lett. 34:L23810. doi: 10.1029/2007GL031694

Sisto, N. P., Ramirez, A. I., Aguilar-Barajas, I., and Magaña-Rueda, V. (2015). Climate threats, water supply vulnerability and the risk of a water crisis in the Monterrey Metropolitan Area (Northeastern Mexico). J. Phys. Chem. Earth 91, 2-9. doi: 10.1016/j.pce.2015.08.015

Smith, K., David, N. P., and Ebook Corporation. (2009). Environmental Hazards: Assessing Risk and Reducing Disaster, 5th Edn. New York, NY: Routlegde.
Trenberth, K. E., Branstator, G. W., Karoly, D., Kumar, D., Lau, N. C., and Ropelewski, C. (1998). Progress during TOGA in understanding and modeling global teleconnections associated with tropical sea surface temperatures. J. Geophys. Res. 103, 14291-14324. doi: 10.1029/97JC01444

Trenberth, K. E., and Fasullo, J. (2007). Water and energy budgets of hurricanes and implications for climate change. J. Geophys. Res. 112:D23107. doi: 10.1029/2006JD008304

Vecchi, G. A., and Knutson, T. R. (2007). On estimates of historical North Atlantic tropical cyclone activity. J. Clim. 21, 3580-3600. doi: 10.1175/2008JCLI2 178.1

Wang, L., Ting, M., Chapman, D., Lee, D. E., Henderson, N., and Yuan, X. (2015). Prediction of northern summer low-frequency circulation using a high-order vector auto-regressive model. Clim. Dyn. 46, 693-709. doi: 10.1007/s00382-015-2607-0

Willoughby, H. E. (1979). Forced secondary circulations in hurricanes. J. Geophys. Res. 84, 3173-3183. doi: 10.1029/JC084iC06p03173

Xu, G., Osborn, T. J., and Matthews, A. J. (2017). Moisture transport by Atlantic tropical cyclones onto the North American continent. Clim. Dyn. 48, 3161-3182. doi: 10.1007/s00382-016-3257-6

Zhang, D. L., and Kieu, C. Q. (2005). Shear- forced vertical circulations in tropical cyclones. Geophys. Res. Lett. 32:L13822. doi: 10.1029/2005GL023146

Conflict of Interest Statement: The authors declare that the research was conducted in the absence of any commercial or financial relationships that could be construed as a potential conflict of interest.

Copyright (C) 2018 Dominguez and Magaña. This is an open-access article distributed under the terms of the Creative Commons Attribution License (CC BY). The use, distribution or reproduction in other forums is permitted, provided the original author(s) and the copyright owner are credited and that the original publication in this journal is cited, in accordance with accepted academic practice. No use, distribution or reproduction is permitted which does not comply with these terms. 